\title{
Timing and outcome of coronary artery bypass grafting in STEMI: on-pump and off-pump dilemma
}

\begin{abstract}
Background: Our objective in this multicenter retrospective study is to discuss the optimum timing for CABG after STEMI. The second question is whether the Off-Pump technique differs regarding the timing or affects the outcome compared to the On-Pump technique.

Methods: Between September 2009 and June 2016 in Saudi German hospitals group in Saudi Arabia and central Hospital BadBerka in Germany, 379 STEMI patients, who were not candidates for or failed PCI; were operated for CABG. 200 (52.77\%) were operated Off-Pump and 179(47.23\%) On -Pump; with an age range of 36-63years. 195 males in the off-pump patients (97.5\%) and 175 males $(97.76 \%)$ in the on-pump patients. we arranged them into 2main groups; group A as off-Pump and group B as on-pump. Both groups were further subdivided into groups A1 (off-pump early surgery; 100 patients), group A2 (offpump late surgery; 100 patients) group B1 (on-pump early surgery; 88 patients) and group B2 (late surgery; 91 patients). We excluded patients with Complicated PCI, Mechanical complications, Cardiogenic shock, Life threatening arrhythmias and Late presentation of ischemia or infarction after PCI.

Results: 25 mortalities occurred in early operated cases. There were no intra-operative mortality in the groups operated late after the infarction, and only one late postoperative mortality in group B2. 9 mortalities in group A1 ( $4.5 \%$ of the off-pump CABG- $9 \%$ of group A1) and 16 mortalities of group B (8.9\% of group B, 15 cases in group B1; $17 \%$ and 1 case in group B2; 1.09\%). There was significant statistical difference between group $\mathrm{A}$ and group $\mathrm{B}, \mathrm{A} 1$ and $\mathrm{A} 2, \mathrm{~B} 1$ and $\mathrm{B} 2$; regarding the intra-and postoperative mortality with $p$-value of $0.004,0.0022,0.001$ intraoperatively and $0.0047,0.001,0.003$ postoperatively. The postoperative duration for mechanical ventilation was longer in group B than in group A, and longer in group A1 compared to group A2. The use of intra-aortic balloon pump was more in group $\mathrm{B}$ than $\mathrm{A}$ and more in $\mathrm{A} 1$ compared to $\mathrm{A} 2$ also more in cases of group $\mathrm{B} 1$ than $B 2$. The use of inotropic support was more in group $B$ than $A$ while it was less in A2 than A1 and more in B1 than B2. The total ICU and hospital stay were longer in cases of B than A and more in $\mathrm{A} 1$ than $\mathrm{A} 2$, also longer in $\mathrm{B} 1$ than $\mathrm{B} 2$. The intra and post operative arrhythmias and complications were more in $\mathrm{A} 1$ than $\mathrm{A} 2$ and in $\mathrm{B} 1$ than $\mathrm{B} 2$.
\end{abstract}

Conclusion: The more we wait after STEMI for surgical intervention for cases not candidate or failed for primary PCI, the better the outcome of surgery With no sharp time limit for postponing the surgery.

Keywords: MI STEMI, PCI, off-pump; timing of CABG
Volume 8 Issue I - 2017

\author{
Tamer Owais, ${ }^{1,3}$ Ashraf Fawzy, ${ }^{2}$ Mohamed \\ Adel,,3 Martin Breuer,' Jurgen Fuchs, ${ }^{4}$ \\ Bernward Lauer,' Thomas Kuntze' \\ 'Heart center, Department of Cardiac Surgery and Cardiology \\ Central Hospital Bad Berka, Germany \\ ${ }^{2}$ Heart center, Department of Cardiac Surgery and Cardiology \\ in Saudi-German Hospital Groups (SGH) in Medinah and Jeddah, \\ Saudi Arabia \\ ${ }^{3}$ Department of Cardio-thoracic Surgery, Cairo university \\ Hospitals, Egypt \\ ${ }^{4}$ Department of Cardiac Anaesthesia Central Hospital Bad \\ Berka, Germany
}

\begin{abstract}
Correspondence: Tamer Owais MD, Department of Cardiac Surgery, Central Clinic Bad Berka, Robert-Koch Allee 9, 99437 Bad Berka, Germany, Email tamerowaiss1976@yahoo.com
\end{abstract}

Received: October 25, 2016 | Published: January 04, 2017

\section{Background}

There is no consensus about the time definitions early or late CABG after acute MI; According to the European system for cardiac operative risk evaluation (EuroSCORE.) for risk stratification; they stated that the safe interval between MI and CABG is 90days. ${ }^{1,2}$ The restoration of the blood flow is important for life saving and decreasing complications of acute myocardial infarction. The prompt regain of the blood flow is difficult using surgical techniques but it is fast by fibrinolysis and best by PCI, which may lead to limitation of the infarct size decreasing the early remodeling, unfortunately late remodeling may lead eventually to LV failure with poor surgical prognosis. ${ }^{3}$ Despite the fast restoration of the blood flow using PCI and fibrinolysis and their superiority to surgery; yet remains surgery as a rescue for special cases as non indicated patients for PCI or partially solved problems by PCI or even failed PCI. ${ }^{4}$

Despite the un-debatable role of surgery in such patients yet still a great debate regarding the timing of surgical revascularization of such patients. ${ }^{5-7}$ The long term and also the short term outcomes for revascularization after STEMI depends on how fast we revascularize; All the available data are based on retrospective studies with lack or even non- available prospective randomized studies. ${ }^{4}$ In cases of elective coronary artery revascularization, there is no debate related to the timing or even the technique weather it is on pump or off-pump, yet in acute STEMI the debate of timing or the technique may affect the survival or later complications as well as the financial resources of the patient, the hospital or the country. ${ }^{7}$ We are concerned with the timing to avoid the remodeling process which may end with heart failure and also the risk of sudden death or re-infarction. As before in the $80 \mathrm{~s}$ of the previous century there was a hypothesis of reperfusion injury after early reperfusion. ${ }^{8,9}$ As a result of ventricular remodeling; the followings may occur: Increased systolic wall tension/stress, reduced diastolic wall tension/stress, reduced myocyte shortening, reduced sub-endocardial perfusion, increase MVo2, dysynchronous depolarization /contraction and these may lead to mitral regurgitation, ventricular aneurysm and ventricular fibrillation. There is no doubt that the increased time interval for revascularization will increase the remodeling process. ${ }^{9-12}$ Surgeons had been debated the time for revascularization starting from 6hours which is not practical, to 24hours, 48hours, 72 hours, one week, 2 weeks and some prefer one month after the MI. ${ }^{13,14}$ There is individual opinions and justifications yet there is almost no debate about the timing of surgery for the following cases; despite the debate of the fate. ${ }^{15}$ 
a. Unsuccessful or complicated PCI.(failure of identification of the culprit vessel or failure to reopen it, failure of stent deployment, perforated coronary artery with tamponade, extensive dissection of the culprit artery) these may represents $2-4 \%$ with the advancement in PCI.

b. Mechanical complications of acute MI; mitral regurgitation, rupture of the free ventricular wall and acute ischemic VSD. In some of those patients, revascularization by early PCI prior to CABG for the culprit vessels may lessen the mortality.

c. Left main; this is not based on randomized studies it is just and observational reports.

d. Late presentation of ischemia or re-infarction after PCI.

e. Cardiogenic shock: with non mechanical complications, mortality may be $80 \%$ without surgical interference, yet the surgical interference carries a high risk of mortality in such patients.

f. Life threatening ventricular arrhythmias: either from a previous scar or a recent MI.

g. Failed thrombolysis. PCI is preferred.

Now to the question of timing; CABG as an emergency in STEMI must be performed before 6hours lapse after the acute event otherwise it must be postponed to variable durations based on the clinical condition and the complications it varies from one day to one month. Off-pump CABG surgery appears to be the optimal treatment strategy for patients with STEMI whenever the preoperative conditions permit and CABG surgery is indicated. ${ }^{16}$ Some authors who defer the surgery up to one month, mostly they use the on-pump technique; and indeed there is no difference regarding the late or early mortality, yet there is an interesting technique which might be more attractive and safe which is the on-pump beating CABG. ${ }^{17-19}$ Comparing both techniques historically regarding revascularization after recent $\mathrm{MI}$; the onpump procedure was the first choice as stated Steven Phillips and his colleagues that early CABG using veins could save the patients. ${ }^{20}$ Other authors had another opinions that fibrinolysis and early PCI are superior with lower mortalities than early surgery as the mortality in early cases exceeded $40 \%$ while after 5 weeks were around $5 \% .{ }^{21}$ Yet some other authors had a different opinion; reporting mortality of $7.6 \%$ in cases operated within 24 hours and $4 \%$ mortality in cases operated 1-7days after the MI concluding that delaying CABG has a bad impact on the mortality and the extension of the MI. ${ }^{22}$ This is not contradicting with the study performed by Sintek et al., ${ }^{23}$ stating the decrease of mortality the more we wait $(4.4 \%$ during the 24 hours, $2.1 \% 3-7$ days and 1.4 after one week to one month) yet the point of late remodeling still needs discussion. ${ }^{23}$ Many authors think that it is safe to perform CABG on-pump at any time as long as the patient is hemodynamically stable, yet the PCI is the first option. ${ }^{24}$

The concept of fast recovery and less use of inotropic support and the safety of the off-pump techniques; theoretically may state that it is better in cases of early CABG compared to the on-pump CABG in such patients. Despite in the past 2 decades there is few studies comparing on and off-pump CABG in recent MI, yet all of them concluded that the early CABG off-pump is more safe compared to on-pump with almost half mortality. ${ }^{25-28}$ Some studies stated the age above 65years old, creatinine more than $2 \mathrm{mg} / \mathrm{dl}$, and elevated systolic pulmonary artery pressure more than $60 \mathrm{mmhg}$; amongst the preoperative conventional variables, as predictive factors for the high mortality in CABG during the acute MI. ${ }^{29}$

\section{Methods}

\section{Patients demography}

Between September 2009 and June 2016 in SGH hospitals group in Saudi Arabia and central Hospital BadBerka in Germany, 379 recent MI cases not candidates for or failed PCI; were operated for CABG; 200 (52.77\%) were operated Off-Pump and 179(47.23\%) On-Pump. We referred to the off-pump patients as group A and to the on- pump as group B; both were further sub grouped as early cases for CABG (1) and late CABG (2) as (A1: 100 cases and A2: 100 cases) (B1: 89 and B2: 90 cases). We operated early cases within the first week of the MI and the late cases operated after one week of MI.

\section{Exclusion criteria}

We excluded cases with complicated PCI, mechanical complications of MI (acute MR or ischemic VSD), late presentation or reinfarction, cardiogenic shock, life threatening ventricular arrhythmias and redo-CABG.

\section{Surgical techniques}

In all groups we use the classic median sternotomy, LITA to LAD and all other targets we used the great saphenous vein for any other targets, we did not utilize the radial artery or the RITA, both the separate vein grafts and sequential vein grafting techniques were utilized, this in all the 4 groups. Off-pump: In all the off-pump cases we used low dose heparin $(150 \mathrm{IU} / \mathrm{Kg})$. We used deep pericardial stitch just below and lateral to the left inferior pulmonary vein to manipulate the heart. We used the Medtronic octopus IV, starting in all cases with the LITA to LAD distal anastomoses of all the other targets. We control the coronary artery proximal to the anastomosis using sialistic rubber blunt needle stitch without need for intracoronary shunts and a humidified $\mathrm{CO} 2$ gas blower for good visualization in some cases we used also a distal controlling sialistic snare to control the back flow. There were no conversion in group A2 but 13 cases in group A1 were converted to on-pump due to severe hemodynamic instability or cardiac arrest during anaesthesia which occurred in 2 cases or arrest during the procedure. In all the off-pump cases using the octopus we did not face the problem of ventricular injury from kissing of the octopus even in the infracted areas.

On-pump: In all the cases we started with the RCA, PDA or the PL then the OMs, Ds and RAMUS, and the last is the LITA to the LAD then the proximal anastomoses to the ascending aorta after declamping the aorta. All the patients in off- and on-pump were followed up by clinical evaluation, ECG, cardiac enzymes, echocardiography, CXR and other Laboratory investigations.

\section{Statistical analysis}

Standard definitions were used for patient variables and outcomes. Categorical variables were expressed as percentages, and continuous variables as mean $\square$ \} SD (range). All statistical analyses were performed using IBM SPSS v. 19.0 software (IBM Corp., New York, USA). Comparisons of the preoperative and follow up results were performed using a two paired $t$-test and the Wilcoxon signed rank test, respectively. A two-sided p-value $<0.05$ was considered to be statistically significant.

\section{Results}

Except for the statistical significant differences between groups $\mathrm{A} 1$ and $\mathrm{A} 2$; and $\mathrm{B} 1$ and $\mathrm{B} 2$ in the preoperative Ejection Fraction, the 
NYHA class and the renal impairment; There were no significant differences in all the groups regarding the demographic data, the existence of Diabetes, Hypertension, Dyslipidemia or current or ex-smoking. None of them revealed any statistical significance in all groups. The preoperative statistically significant differences are related to the shock stage in early operated cases where the $\mathrm{EF} \%$, the NYHA class and the renal functions are affected to a great extent in groups A1 and B1.

\section{Demographic data}

Table $1 \& 2$

\section{Operative data}

Table $3 \& 4$

Table I Preoperative variables in relation to number of patients

\begin{tabular}{|c|c|c|c|c|}
\hline Variables & Group A I & Group A2 & Group B I & Group B2 \\
\hline & $\begin{array}{l}\text { Number of patients } 100 \\
\text { cases }\end{array}$ & $\begin{array}{l}\text { Number of patients } 100 \\
\text { cases }\end{array}$ & $\begin{array}{l}\text { Number of patients } 89 \\
\text { cases }\end{array}$ & $\begin{array}{l}\text { Number of patients } 90 \\
\text { cases }\end{array}$ \\
\hline Mean age & $48 \pm 10$ & $50 \pm 11$ & $51 \pm 12$ & $47 \pm 11$ \\
\hline \multirow[t]{2}{*}{ Gender } & 97males & 98 males & 89 males & 86 males \\
\hline & 3 females & 2 females & 0 females & 4 females \\
\hline $\mathrm{EF} \%$ & $31 \pm 10$ & $45 \pm 11$ & $44 \pm 12$ & $32 \pm 11$ \\
\hline NYHA class & $3.1 \pm 0.7$ & $1.8 \pm 0.5$ & $3.3 \pm 0.5$ & $1.6 \pm 0.5$ \\
\hline \multirow[t]{5}{*}{ Angiographic characteristics } & Multivessel & Multivessel 90 cases & Multivessel 83cases & Multivessel \\
\hline & 88 cases & & & 81 cases \\
\hline & 2vessels I Icases & 2vessels 9cases & 2 vessels 6 cases & 2vessels 9cases \\
\hline & Single vessel Icase & Single vessel I case & Single vessel 0 case & Single vessel 0 case \\
\hline & Left main 5 cases & Left main 3 cases & Left main 3 cases & Left main 4cases \\
\hline Hypertension & 43 cases & 39 cases & 44cases & 4 I cases \\
\hline Smoking & 64 cases & 61 cases & 55 cases & 59 cases \\
\hline Family history & 37 cases & 40 cases & 38 cases & 35 cases \\
\hline Dyslipidemia & 49 cases & 56 cases & 53 cases & 50 cases \\
\hline COPD & 4cases & 7 cases & 4cases & 5 cases \\
\hline Peripheral vascular disease & Icase & 3cases & Ocase & 2 cases \\
\hline Renal impairment & 7 case & 2 cases & 6cases & Icase \\
\hline
\end{tabular}

Table 2 Preoperative variables in relation to statistics

\begin{tabular}{llllll}
\hline Variables & A,B & AI,A2 & B I,B2 & AI,B I & A2,B2 \\
\hline Mean age & 0.5 & 0.4 & 0.49 & 0.39 & 0.52 \\
Gender & 0.52 & 0.57 & 0.3 & 0.34 & 0.5 \\
EF\% & 0.03 & 0.002 & 0.0019 & 0.38 & 0.4 \\
NYHA Class & 0.47 & 0.0019 & 0.002 & 0.09 & 0.08 \\
Angiographic characteristics & & & & & \\
Multivessels & 0.1 & 0.13 & 0.1 I & 0.1 & 0.15 \\
& 0.07 & 0.09 & 0.08 & 0.067 & 0.07 \\
2vessels & 0.33 & 0.4 & 0.4 & 0.39 & 0.5 \\
Single vessel & 0.043 & 0.05 & 0.045 & 0.05 & 0.049 \\
Left main & & & & & 0.33 \\
Hypertension & 0.42 & 0.39 & 0.2 & 0.4 & 0.37 \\
Smoking & 0.5 & 0.4 & 0.5 & 0.48 & 0.43 \\
Family history & 0.71 & 0.6 & 0.53 & 0.5 & 0.6 \\
Dyslipidemia & 0.7 & 0.6 & $0.4 I$ & 0.49 & 0.05 I \\
COPD & 0.05 & 0.07 & 0.06 & 0.05 & 0.6 \\
Peripheral vascular disease & 0.3 & 0.26 & 0.31 & 0.7 & 0.4 \\
Renal impairment & 0.2 & 0.003 & 0.003 & 0.4 & \\
\hline
\end{tabular}

Table 3 Operative data in relation to number of patients

\begin{tabular}{|c|c|c|c|c|}
\hline Variables & Group Al & Group A2 & Group B I & Group B2 \\
\hline Time lapse from the acute $\mathrm{MI}$ to the day of surgery & 6hours-one week & I week-4weeks & 6hours-one week & Iweek-4weeks \\
\hline OR duration & $4 \mathrm{hrs} . \pm 22 \mathrm{~min}$ & $3 \mathrm{hrs} \pm 24 \mathrm{~min}$ & $5 \mathrm{hrs} \pm 45 \mathrm{~min}$ & $4 \mathrm{hrs} \pm 38 \mathrm{~min}$ \\
\hline OR inotropes & 89patients & 32patients & 9lpatients & 40patients \\
\hline LITA & 98 patients & 100patients & 85patients & 89 patients \\
\hline Number of vein grafts & $3.1 \pm 0.87$ & $3.3 \pm 0.76$ & $3.4 \pm 0.83$ & $3.3 \pm 0.85$ \\
\hline \multicolumn{5}{|l|}{ IABP } \\
\hline Pre-operative & I7cases & Ocases & 15 cases & Icase \\
\hline Intra-operative & 4cases & Ocases & I I cases & Ocase \\
\hline Post-operative & 7 cases & Ocases & 9 case & Ocase \\
\hline Weaning off-bypass & $\begin{array}{l}\text { I } 3 \text { cases converted to on- } \\
\text { pump for support }\end{array}$ & 0 conversion & $\begin{array}{l}2 \text { l caes difficult } \\
\text { weaning }\end{array}$ & $\begin{array}{l}3 \text { cases difficult } \\
\text { weaning }\end{array}$ \\
\hline \multicolumn{5}{|l|}{ Intra-operative arrhythmias } \\
\hline Atrial & I7cases & 6 cases & 23 cases & 18 cases \\
\hline Ventricular & 6cases & Ocase & I I cases & 3 cases \\
\hline
\end{tabular}

Citation: Owais T, Fawzy A, Adel M, et al.Timing and outcome of coronary artery bypass grafting in STEMI: on-pump and off-pump dilemma.J Cardiol Curr Res. 20I7;8(I):I-6. DOI: I0.15406/jccr.20I7.08.00266 
Table 4 Operative data in relation to statistics

\begin{tabular}{llllll}
\hline Variables & A,B & AI,A2 & BI,B2 & AI,BI & A2,B2 \\
\hline Time from acute MI to day Of surgery & 0.3 & 0.001 & 0.001 & 0.9 & 0.89 \\
OR duration & 0.07 & 0.05 & 0.06 & 0.05 & 0.04 \\
OR inotropes & 0.63 & 0.0032 & 0.003 & 0.7 & 0.49 \\
LITA & 0.4 & 0.34 & 0.39 & 0.42 & 0.4 \\
Number of vein grafts & 0.5 & 0.44 & 0.41 & 0.4 & 0.53 \\
IABP & & & & & \\
Preoperative & 0.6 & 0.0013 & 0.002 & 0.7 & 0.9 \\
Intra-operative & 0.003 I & 0.002 & 0.0018 & 0.003 & 0.9 \\
Post-operative & 0.47 & 0.0021 & 0.002 & 0.0015 & 0.9 \\
Weaning off bypass & - & - & 0.001 & - & - \\
Conversion to on-pump & & 0.0022 & & & \\
Intra-operative arrhythmias & & & & & \\
Atrial: ventricular & 0.0041 & 0.004 & 0.09 & 0.9 & 0.0032 \\
Ventricular & 0.003 & 0.001 & 0.002 & 0,004 & 0.0047 \\
\hline
\end{tabular}

Table 5 Postoperative data in relation to number of patients

\begin{tabular}{|c|c|c|c|c|}
\hline Variables & GroupAI & GroupA2 & GroupB I & GroupB2 \\
\hline \multicolumn{5}{|l|}{ ICU inotropes } \\
\hline$\geq 0.1 \mu$ & 30 cases & Icase & 33 cases & 6 cases \\
\hline$\leq 0.1 \mu$ & 67 cases & 9cases & 66 cases & I7cases \\
\hline Mechanical ventilation (hrs) & $21 \pm 11$ & $4 \pm 1.5$ & $23 \pm 10$ & $8 \pm 3.3$ \\
\hline Blood transfusion (units of packed RBCs) & $3.4 \pm 1.7$ & $1.3 \pm 0.9$ & $5.3 \pm 2.2$ & $2.6 \pm 1.8$ \\
\hline Strokes & 0 & 0 & 3 cases & 0 \\
\hline Chest infection & 7 cases & 2 & 13 cases & 6cases \\
\hline Renal impairment & 3 cases & 0 & 12 cases & I case \\
\hline GIT complications & 0 & 0 & 2cases upper GIT bleeding and melena & 0 \\
\hline Ventricular arrhythmias & 6 cases & 0 & 13 cases & 0 \\
\hline $\mathrm{AF}$ & 23 cases & 5 cases & 4 I cases & 12 cases \\
\hline ICU stay (days) & $5.6 \pm 2.2$ & $2.6 \pm 1.4$ & $8.6 \pm 3.7$ & $3.1 \pm 0.9$ \\
\hline Hospital stay (days) & $14.3 \pm 3.8$ & $6.9 \pm 2.3$ & $19.4 \pm 4.3$ & $8.9 \pm 2.4$ \\
\hline \multicolumn{5}{|l|}{ Mortality } \\
\hline Intraoperative & 3 cases & 0 & 6 cases & 0 \\
\hline Postoperative & 6 cases & 0 & 9cases & $\mathrm{I}$ \\
\hline
\end{tabular}

Table 6 Postoperative data in relation to statistics

\begin{tabular}{llllll}
\hline Variables & A,B & AI,A2 & BI,B2 & AI,B I & A2,B2 \\
\hline ICU inotropes: & & & & & \\
$\geq 0.1 \mu$ & 0.089 & $0.00 I$ & 0.0012 & 0.9 & 0.0048 \\
$\leq 0.1 \mu$ & 0.0047 & 0.003 & 0.0039 & 0.77 & 0.0033 \\
Mechanical ventilation (hours) & 0.07 & 0.003 & 0.0032 & 0.62 & 0.0047 \\
Blood transfusion(units of packed RBCs) & 0.005 & 0.0041 & 0.004 & 0.04 & 0.0036 \\
Strokes & 0.003 & 0.89 & 0.0021 & 0.003 & 0.089 \\
Chest infection & 0.0046 & 0.0024 & 0.004 & 0.0032 & 0.0016 \\
Renal impairment & 0.001 & 0.003 & 0.0001 & 0.0043 & 0.79 \\
GIT complications & 0.0048 & 0.96 & 0.0048 & 0.0048 & 0.96 \\
Ventricular arrhythmias & 0.0017 & 0.0012 & 0.001 & 0.004 & 0.0001 \\
AF & & & & & \\
ICU stay (days) & 0.0049 & 0.0014 & 0.003 & 0.072 & 0.06 \\
Hospital stay (days) & 0.0041 & 0.0031 & 0.0046 & 0.08 & 0.083 \\
Mortality & & & & & \\
Intraoperative & 0.004 & 0.0022 & 0.001 & 0.5 & 0.7 \\
Postoperative & 0.0047 & 0.001 & 0.003 & 0.4 & 0.7 \\
\hline
\end{tabular}

There was statistical differences between A1 and A2; B1and B2 pre-intra and postoperative use of IABP, as patients in groups A1 and B1 were unstable hemodynamically since the time of presentation with STEMI till after surgery. The weaning off-bypass was difficult in 23 cases in group B1 while only 3 cases had difficult weaning in B2 (p 0.001). In group A2 there was 0 conversion rate to on-pump while in A1 it was 13 cases (13\%) (p 0.0022). The intra-and postoperative ventricular arrhythmias were significant in groups $\mathrm{B}$ more than $\mathrm{A}, \mathrm{A} 1$ more than $\mathrm{A} 2$ and $\mathrm{B} 1$ more than $\mathrm{B} 2$.

\section{Post-operative data}

We noticed an increased dosages of inotropic supports in groups $\mathrm{A} 1$ and $\mathrm{B} 1$ than $\mathrm{A} 2$ and $\mathrm{B} 2$. The differences in the use of inotropic supports in group A was significantly lower in group B as a whole. The duration of mechanical ventilation was longer in groups A1 compared to A2 and longer in B1 than B2. More blood was transfused in the on-pump compared to the off-pump and more in A1 compared to A2. The incidence of strokes, chest infection, renal impairment, arrhythmias, ICU and hospital stay were higher in group B than A, and higher in $\mathrm{A} 1$ than $\mathrm{A} 2$ and more in $\mathrm{B} 1$ than $\mathrm{B} 2$. 
The mortality rate was higher in group B than A both intra and post-operatively (P 0.004 and 0.0047 ) respectively. More mortality in group A1 than A2 intra-and postoperatively (p 0.0022 and 0.003 ). Also higher mortalities occurred in group B1 more than B2 both intraand post operatively (p 0.001 and 0.003 ).

\section{Discussion}

Most of the studies focused on the timing only which is a very hard task, yet we here focused also on the technique trying to conclude wether the technique will lead us to a safe early CABG or not. In the past years, the invasive rescue and primary PCI saved lives avoiding the risk of early CABG. But still some patients who are not candidates for primary PCI are in great risk to do CABG because of fresh infraction risks or because of the risk of waiting till remodeling which might might end in heart failure or ventricular aneurysm. ${ }^{30,31}$ In our work there was a mortality range of $9 \%$ in both groups with almost no differences regarding the technique. It was higher $17 \%$ in early on-pump cases and $9 \%$ in early off-pump cases. Despite the improved mortality rate which in some other studies on-pump was $19 \%$ in early operated cases within the first 72 hours after the onset of the infarction, ${ }^{32}$ we can note the same range which is not improved with time and more pharmaceutical and surgical innovations.

In our study we found that the more we wait the better the results,with better outcomes after the first week of the acute MI. In other studies they stated the $4^{\text {th }}$ and $6^{\text {th }}$ days of the acute phase as a safe time, while some others referred to the 4 weeks or even longer, as a very safe time. ${ }^{33,27}$ Some other studies revised the difference between the STEMI and NSTEMI and they concluded that the NSTEMI is more risky in early operated cases than the STEMI. ${ }^{34}$ Yet we focused only on STEMI cases, and we excluded the NSTEMI cases.

The predictors of the outcome are the preoperative clinical condition and the echo result with the kidney functions; all were jeopardized in the early operated cases weather they are on or offpump with a bad outcome after surgery in both groups. Despite we excluded cases with cardiogenic shock, some other studies included them with a high mortality up to $59 \% .{ }^{35-37}$ There are other studies considering different predictors for the outcome of $\mathrm{CABG}$ in the acute phase of MI like the use of different kinds of cardioplegia in on-pump cases; comparing the antegrade/retrograde blood cardioplegia versus the antegrade crystalloid cardioplegia, proving better results with the first one yet it was not in the scoop of our study. ${ }^{38}$ We also did not find any impact of the level of troponin or other cardiac enzymes on the outcome whether in early CABGs which was concomitant with other studies. ${ }^{39} \mathrm{We}$ found better outcomes in all cases performed late after the acute phase of MI in STEMI patients using both on-pump or off-pump techniques. Despite there was relatively better results using the off-pump in early cases than in on-pump, regarding the intra and postoperative arrhythmias, GIT complications, renal impairment, chest infections, strokes, blood transfusion, use of IABP, the dosage of inotropic supports and the intra and postoperative mortality; yet there was statistically significant differences among the same technique used whether it was on or off pump; in favor of the late operated cases. The more time we waited the better was the result.

\section{Conclusion}

It is safer to post pone stable or even unstable monitored patients in STEMI for surgical intervention. If we were obliged to perform CABG in the early phase of the acute MI, it is better do it off-pump. More studies are required to sharpen the time after STEMI to perform the CABG.

\section{Acknowledgments}

None.

\section{Conflicts of interest}

Author declares there are no conflicts of interest.

\section{Funding}

None.

\section{References}

1. Nashef SA, Roques F, Michel P, et al. Eurpean system for cardiac operative risk evaluation(EuroSCORE). Eur J Cardiotorac Surg. 1999;16(1999):9-13.

2. Dumbor L Ngaage, Franco Sogliani, Augustine Tang. Early and late prognostic implications of coronary artery bypass timing after myocardial infarction. Eur J Cardiothorac Surg. 2013;43(3):549-554.

3. Hannan EL, Racz MJ, Arani DT, et al. Short-and long-term mortality for patients undergoing primary angioplasty for acute myocardial infarction. J Am Coll Cardiol. 2000; 36(4):1194-1201.

4. Raghavan R, Benzaquen BS, Rudski L. Timing of bypass surgery in stable patients after acute myocardial anfarction. Can J Cardiol. 2007;23(12):976-982.

5. Pocock SJ, Henderson RA, Rickards AF, et al. Meta-analysis of randomised trials comparing coronary angioplasty with bypass surgery. Lancet. 1995;346:1184-1189.

6. Hochberg MS, Parsonnet V, Gielchinsky I, et al. Timing of coronary revascularization after acute myocardial infarction. Early and late results in patients revascularized within seven weeks. J Thorac Cardiovasc Surg. 1984;88(6):914-921.

7. Braxton JH, Hammond GL, Letsou GV, et al. Optimal timing of coronary artery bypass graft surgery after acute myocardial infarction. Circulation. 1995;92(Suppl II):II66-68.

8. Gertler JP, Elefteriades JA, Kopf GS, et al. Predictors of outcome in early revascularization after acute myocardial infarction. Am J Surg. 1985;149(4):441-444.

9. Voisine P, Mathieu P, Doyle D, et al. Influence of time elapsed between myocardial infarction and coronary artery bypass grafting surgery on operative mortality. Eur J Cardiothorac Surg. 2006;29(3):319-323.

10. Carluccio E, Biagioli P, Alunni G, et al. Patients with hibernating myocardium show altered left ventricular volumes and shape, which revert after revascularization: Evidence that dyssynergy might directly induce cardiac remodeling. J Am Coll Cardiol. 2006;47(5):969-977.

11. Greenberg B, Quinones MA, Koilpillai, et al. Effects of long-term enalapril therapy on cardiac structure and function in patients with left ventricular dysfunction. Results of the SOLVD echocardiography substudy. Circulation. 1995;91:2573-2581.

12. Vanoverschelde JL, Depré C, Gerber BL, et al. Time course of functional recovery after coronary artery bypass graft surgery in patients with chronic left ventricular ischemic dysfunction. Am J Cardiol. 2000;85(12):1432-1439.

13. Katz NM, Kubanick TE, Ahmed SW, et al. Determinants of cardiac failure after coronary bypass surgery within 30 days of acute myocardial infarction. Ann Thorac Surg . 1986;42(6):658-663.

14. Salem BI, Gowda S, Haikal M, et al. Early percutaneous transluminal coronary angioplasty or coronary bypass surgery following thrombolytic treatment of acute myocardial infarction. Chest. 1987;91(5):648-653.

15. Oz M Shapira, John A Bittal. Coronary artery bypass graft surgery after acute ST elevation myocardial infarction. Ministry of health KSA. 2014. 
16. Dioguardi P. Off-Pump Coronary Artery Bypass Grafting in Patients with St-Segment Elevation Myocardial Infarction. $J$ Cardiovasc Dis Diagn. 2013.

17. Izumi $\mathrm{Y}$, Magishi $\mathrm{K}$, Ishikawa $\mathrm{N}$, et al. On-pump beating-heart coronary artery bypass grafting for acute myocardial infarction. Ann Thorac Surg. 2006;81(2):573-576.

18. Wasvary H, Shannon F, Bassett J, et al. Timing of coronary artery bypass grafting after acute myocardial infarction. Am Surg. 1997;63(8):710-715.

19. Fattouch K, Runza G, Moscarelli M, et al. Graft patency and late outcomes for patients with ST-segment elevation myocardial infarction who underwent coronary surgery. Perfusion. 2011;26(5):401-408.

20. Phillips SJ, Kongtahworn C, Zeff RH, et al. Emergency coronary artery revascularization: a possible therapy for acute myocardial infarction. Circulation. 1979;60(2):241-246.

21. Hochberg MS, Parsonnet V, Gielchinsky I, et al. Timing of coronary revascularization after acute myocardial infarction. Early and late results in patients revascularized within seven weeks. J Thorac Cardiovasc Surg. 1984;88(6914-6921.

22. Floten HS, Ahmad A, Swanson JS, et al. Long-term survival after postinfarction bypass operation: early versus late operation. Ann Thorac Surg. 1989;48(6):757-762.

23. Sintek CF, Pfeffer TA, Khonsari S. Surgical revascularization after acute myocardial infarction. Does timing make a difference? J Thorac Cardiovasc Surg. 1994;107(5):1317-1321.

24. Lee DC, Oz MC, Weinberg AD, et al. Optimal timing of revascularization: transmural versus nontransmural acute myocardial infarction. Ann Thorac Surg. 2001;71(4):1197-1202.

25. van Dijk D, Nierich AP, Jansen EW, Nathoe HM, Suyker WJ, et al (2001) Early outcome after off-pump versus on-pump coronary bypass surgery: results from a randomized study. Circulation 104(15): 17611766.

26. Khan NE, De Souza A, Mister R, Flather M, Clague J, et al. (2004) A randomized comparison of off-pump and on-pump multivessel coronary-artery bypass surgery. N Engl J Med 350(1): 21-28

27. Mohr R, Moshkovitch Y, Shapira I, et al. Coronary artery bypass without cardiopulmonary bypass for patients with acute myocardial infarction. $J$ Thorac Cardiovasc Surg . 1999;118(1):50-56.

28. Locker C, Shapira I, Paz Y, et al. Emergency myocardial revascularization for acute myocardial infarction: survival benefits of avoiding cardiopulmonary bypass. Eur J Cardiothorac Surg. 2000;17(3):234-238.
29. Mejía OA, Lisboa LA, Tiveron MG, et al. coronary artery bypass grafting in acute myocardial infarction: analysis of predictors of inhospital mortality. Rev Bras Cir Cardiovasc. 2012;27(1):66-74.

30. Raghavan R, Benzaquen BS, Rudski L. Timing of bypass surgery in stable patients after acute myocardial infarction. Can J Cardiol. 2007;23(12):976-982.

31. Alter DA, Tu JV, Autsin PC, et al. Waiting times, revascularization modality, and outcomes after acute myocardial infarction at hospitals with and without on-site revascularizations facilities in Canada. $\mathrm{J} \mathrm{Am}$ Coll Cardiol. 2003;42(3):410-419.

32. Jatene FB, Nicolau JC, Hueb AC, et al. Fatores prognósticos da revascularização na fase aguda do infarto agudo do miocárdio. Rev Bras Cir Cardiovasc. 2001;16(3):195-202.

33. Lee DC, Oz MC, Weinberg AD, et al. Appropriate timing of surgical intervention after transmural acute myocardial infarction. J Thorac Cardiovasc Surg. 2003;125(1):115-119.

34. Lee DC, Oz MC, Weinberg AD, et al. Optimal timing of revascularization: transmural versus nontransmural acute myocardial infarction. Ann Thorac Surg. 2001;71(4):1197-1202.

35. Sergeant P, Blackstone E, Meyns B, et al. First cardiological or cardiosurgical reintervention for ischemic heart disease after primary coronary artery bypass grafting. Eur J Cardiothorac Surg . 1988;14(5):480-487.

36. Hochman JS, Sleeper LA, Webb JG, et al. Early revascularization in acute myocardial infarction complicated by cardiogenic shock. SHOCK Investigators. Should We Emergently Revascularize Occluded Coronaries for Cardiogenic Shock. N Engl J Med. 1999;341(9):625-634.

37. Rastan AJ, Eckenstein JI, Hentschel B, et al. Emergency coronary artery bypass graft surgery for acute coronary syndrome: beating heart versus conventional cardioplegic cardiac arrest strategies. Circulation. 2006;114(1 Suppl):I477-1485.

38. Pichon H, Chocron S, Alwan K, et al. Crystalloid versus cold blood cardioplegia and cardiac troponin I release. Circulation. 1997;96(1):316-320.

39. Hagl C, Khaladj N, Peterss S, et al. Acute treatment of ST-segmentelevation myocardial infarction: is there a role for the cardiac surgeon? Ann Thorac Surg. 2009;88(6):1786-1792. 